\title{
Learning Teaching Practices: the Role of Critical Mentoring Conversations in Teacher Education
}

\author{
Christine J Edwards-Groves \\ Correspondence: Christine J Edwards-Groves, School of Education, Charles Sturt University, Wagga Wagga, NSW, \\ 2650, Australia. Tel: 61-269-332-444. E-mail: cgroves@csu.edu.au
}

\author{
Received: January 6, 2013 Accepted: January 21, 2013 Online Published: February 10, 2014 \\ doi:10.11114/jets.v2i2.343 \\ URL: http://dx.doi.org/10.11114/jets.v2i2.343
}

\begin{abstract}
This paper examines the role of dialogue for learning about and enacting teaching within critical mentoring conversations between pre-service teachers (PSTs) and classroom teacher mentors. The paper draws on a broader two-year intervention study, conducted in a teacher education faculty in rural Australia. The empirical study centred on the development of quality classroom interactions and dialogic pedagogies of PSTs as they practice learning to teach in authentic school-based situations; these are issues of practical concern for education globally. The paper presents an in-depth analysis of a single case study of mentoring conversations and follow-up interviews with PSTs and their teacher mentor. The transcript analysis - presented as talk-in-interaction - enabled the close and continual examination of participants' practices and afforded the opportunity to elicit the intricacies of social actions to elicit themes about: i) the conduct of mentoring conversations, ii) how mentoring unfolded discursively as sequences of interaction, and iii) how these produced displays of learning among PSTs. Results reveal firstly how mentoring conversations unfold structurally in activity time space and how these were learning conversations which were pedagogical, collaborative, analytic, dialogic and evidence-based. Critical mentoring conversations enabled PSTs to build a strong practice-theory base around the classroom exchanges experienced, observed and critiqued.
\end{abstract}

Keywords: dialogic pedagogies, mentoring, mentoring conversations, practice architectures, responsive feedback, teacher education practices

\section{Introduction}

\subsection{The Issue of Concern}

The practice of mentoring in education as an approach for learning and developing teaching practice is one which is commonly practiced to assist both newly qualified teachers and pre-service teachers (PSTs) to develop and enter the profession as critical inquirers and knowledgeable practitioners. This paper focuses on mentoring practices in teacher education. Mentoring and supervising PSTs in the context of their professional placements (or school-based practicum) is a practice commonly conducted and researched across the globe. For many decades, international research has shown that mentoring by supervising or associate teachers plays a pivotal role in supporting the development of PSTs practices, their sense of identity and their connection to the profession (for example, Kwan \& Lopez, 2005; McIntyre, 1991; Timperley, 2001; Zeichner, 1990). Furthermore, the research has established that 'mentoring plays an important role in enhancing novice teachers' opportunities to learn within the contexts of teaching' (Lai, 2005, p.12).

Within this landscape, the conduct of mentoring research in teacher education has largely focused on the broader purposes of mentoring practices and the relational or social-political dimensions of mentoring practice (Ambrosetti, \& Dekkers, 2010; Le Cornu, 2010) without interrogating the specific topics of talk (or cultural-discursive dimensions) within mentoring interactions between classroom teacher mentors and PSTs. Mentoring in professional workplace contexts is well described and defined (for example Eby, McManus, Simon \& Russell, 2000; Allen, 2003). However, in the specific context of pre-service teacher education, clarity about how mentoring actually happens within the social context of moment-by-moment interactions occurs is scarce (Lai, 2005; Hall, Draper, Smith \& Bullough Jr, 2008). Additionally, current research rarely addresses the phenomenon of 'mentoring' from a practice theory perspective. This paper addresses this gap.

Mentoring has been described as 'both a relationship and a process' (Kwan \& Lopez, 2005, p.276) and has been conceptualised by Finnish researchers as a dialogue (Heikkinen, Jokinen, \& Tynjälä, 2008). Research suggests it is a 
multidimensional practice aimed to facilitate the co-construction of informed enactment of teaching as experienced classroom teachers or university academics, as 'more knowledgeable experts' (Bransford, Brown \& Cocking, 1999) guide teacher development through practice and theory development (Graham \& Thornley, 2000; Hennissen, et. al., 2011; Jaipal, 2009; Strong \& Baron, 2004). Research conducted in 2001 by Helen Timperley, New Zealand, examined the role conversations between student teachers and their teacher mentors had for promoting learning; she described these interactions as 'mentoring conversations' (2001, p.111). Drawing partly on the work of Timperley (2001), this paper examines the central role that mentoring conversations has on learning teaching practice. Specifically, it looks at the overlapping nature of 'dialogue for learning' on two levels: first, the role of dialogue in mentoring conversations among PSTs and teacher mentors; and second how, through these conversations, PSTs develop understandings about 'dialogic pedagogies' when it is the explicit object of learning.

The paper draws on a broader two-year empirical study, conducted in a teacher education faculty in rural Australia. It centred on the development of quality classroom interactions and dialogic pedagogies of PSTs - issues of practical concern for education globally (Collins, 2004; Edwards-Groves \& Hoare, 2012; Egan, 2009; Fenimore-Smith, 2004; Grossman, Hammerness, \& McDonald, 2009; Woodruff, \& Brett, 1999). In fact, classroom talk and developing dialogic teaching practices in classrooms remains a 'taken-for-granted' and an under-examined dimension of pre-service teacher education courses (Edwards-Groves \& Hoare, 2012). Furthermore, explicit instruction along focused opportunities for 'practicing' engaging in dialogic pedagogies with students in classrooms, currently receives little dedicated space in many pre-service education courses (Edwards-Groves \& Hoare, 2012). This neglect leads to a tendency for PSTs to enact a default practice in placement classrooms based on replicating known patterns of interaction of those observed and those experienced in their own education (Love, 2009).

The role of dialogue for learning and thinking as a fundamental classroom practice was the explicit focus for the learning conversations between teacher mentors and PSTs in a teacher education project entitled Talking to Learn (see Edwards-Groves \& Hoare, 2012). These conversations took place in classrooms after PSTs practiced interacting with small groups of students, providing an authentic context for 'informed participation' in teaching practice (Edwards, Gilroy \& Hartley, 2004). In the particular research site interacting with students in classrooms was not the focus of explicit instruction in the practicum placements for PSTs; it was taken-for-granted that PSTs could interact with students in classrooms. The article therefore has two practical aims: first, the investigation of the impact that participating in focused mentoring conversations has on the development of specific teaching practices among PSTs development; and second, on the development of understandings about classroom interaction and dialogic pedagogies among PSTs (from the beginning semester of their four year Bachelor of Education degree).

Theoretically, the paper draws on the theory of practice architectures (Kemmis \& Grootenboer, 2008; Kemmis, Wilkinson, Edwards-Groves, Hardy, Grootenboer \& Bristol, 2014) which proposes that practice is informed and shaped by particular cultural-discursive arrangements (the sayings of a practice), material-economic arrangements (the doings of a practice) and social-political arrangements (the relatings encountered in practice). These prefigure, but do not determine, practice. Through empirical material, the paper seeks to provide dynamic descriptions of the particular conditions that stimulate and support the development of PSTs of the specific practice of teaching using dialogic pedagogies through mentoring conversations.

\subsection{A Practice Perspective - the Theory of Practice Architectures and 'Learning' Practice}

In recent years, new perspectives on practice theory offer an alternative for conceptualising and interpreting practices; these focus on the sociality of practices and the practical realities or 'happening-ness' when people encounter one another in everyday social life. To understand this, Green (2009), Kemmis and Grootenboer (2008), Kemmis, et al. (2014) and Schatzki (2002) among others, have attempted to show how practices - like practices of teaching, learning and learning to teach - are held in place by distinctive arrangements that enable and constrain the kinds of language (sayings), activities (doings), and relationships (relatings) encountered in any kind of practice. Kemmis \& Grootenboer (2008) described this as the theory of practice architectures according to which practices consist of sayings, doings and relatings that hang together in the project of a practice. Practices shape and are shaped, in interrelated ways, by the arrangements (site-based conditions) and the historical traces of past educational practices that pertain in particular sites (such as the teaching and learning approaches in particular classrooms at a school or at university).

Specifically, these practice arrangements form the intersubjective mechanisms for understanding how educational practices take place. This view of practices aims to provide the means to analyse practices like mentoring conversations and to discover the conditions (the practice architectures) which make them possible. Therefore, learning practices like teaching come into being by:

i. entering and coming to understand the complexities of the distinctive form of socially established cooperative human activity; 
ii. being initiated into arrangements characteristic of the practice, and being stirred into the language, the activity and the relational dimensions of practices (Kemmis, et al., 2014) often through 'legitimate peripheral participation' (Lave \& Wenger, 1991); and by

iii. practicing and theorising practice as an interconnected web of sayings, doings and relatings (Kemmis \& Grootenboer, 2008) which shape and prefigure what students in classrooms, teachers and PSTs can and will do; and to a certain degree, what they understand 'their practice' to be.

Therefore, understanding learning practices - such as pre-service education students learning to become teachers requires understanding how practice arrangements (for instance, mentoring conversations) also furnish the substance for the sayings, doings and relatings which together constitute teaching and make them comprehensible to those who enter and inhabit it.

\subsection{Mentoring as Dialogic Pedagogical Practice}

In the past, the role of mentoring has been described as teacher mentors guiding the interpretation of PSTs observations of pedagogical procedures and teaching strategies (Grove, Strudler \& Odell, 2004; Hennissen, et. al., 2011; Martinez, 1998). A synthesis of other research extends this view to encompass the multiple roles of mentors such as being a 'critical friend' (Day, 1999), or a 'role model, friend, encourager, counselor, nurturer, evaluator or expert who model specific teaching practices' (Jaipal, 2009, p. 257; Hudson, 2004). Mentoring has been described as simply as a 'helping' activity (Clutterbuck \& Ragins, 2002) or as more dynamic instances of 'co-learning' (Jaipal, 2009) or 'reciprocal mentoring' (Grove, et. al., 2004) whereby a reciprocal relationship exists between the development of professional practice knowledge among pre-service and their associate or supervising teachers.

Mentoring as co-learning or a more democratic practice re-envisions the supervisory nature of the mentoring process. The mentoring relationship is often also one of supervision where the formal assessment of PSTs often drives the relationship (Tillem, Smith, \& Leshem, 2011). As a democratic practice, however, it forms

... a collaborative, dynamic, and creative partnership of coequals, founded on openness, vulnerability, and the ability of both parties to take risks with one another beyond their professional roles. Relationships become opportunities for dialogue, and expert and learner become arbitrary delineations. ... The relationship becomes interdependent. (Darwin, 2000, p. 206)

What Darwin is describing here is the dynamic interplay between the cultural-discursive (sayings or language), the material-economic (doings or activities such as participating in opportunities for dialogues) and social-political (relatings such as collaborative and interdependent relationships as coequals) dimensions of the practice arrangements which exist in mentoring practices. These arrangements exist as dialogic practices (Heikkinen, Jokinen \& Tynjälä, 2010) which are iterative, and proposed by Edwards (1995) as the constant 'zigzag of action and discussion' (p 598) with someone more expert in the practice. She suggested that that action - as a form of evidence - followed by discussion acts as a pedagogical practice that helps PSTs

translate their experiences into frames provided by public knowledge and to acquire the more powerful language frameworks so that they become insiders in the professional discourse and able to articulate it and keep it public and open to scrutiny rather than tacit or private. (Edwards, 1995, p. 598)

Although the literature across many disciplines has a long history of describing and defining mentoring (from for example Roche (1978) to Jacobi (1991) to Heikkinen, et.al. 2010), these broad attempts to define mentoring do not and cannot serve the purposes of all fields (Merriam, 1983). Rather, mentoring should be understood in connection to its substance and function in the particular projects, circumstances and sites in which it is enacted. Therefore, the results of this study may contribute to defining or re-defining the kinds of mentoring that happens between PSTs and their mentors.

\subsection{Mentoring Conversations}

A large proportion of the work of mentors is accomplished through talk-in-interaction (Sacks, 1974), and so understanding how this interaction unfolds in the 'happeningness' of occasions of mentoring is necessary. The focus and quality of talk within dialogues in mentoring conversations - also described as mentoring dialogues (Hennisson, et al. 2011) - is pivotal for developing strong theory practice connections (Hudson, 2004; Timperley, 2001). In particular, the research conducted by Timperley focused on the quality of interactions between mentors and PSTs and how these can be improved with explicit mentor training. From this, the research presented in this paper is informed by Timperley's attention to quality interactions in the context of mentoring conversations. In particular, the use of evidence and open sharing of valid information in a cycle of ongoing inquiry as the basis for conversations between the teachers and PSTs (as described by Timperley, 2001, p. 112) had implications for structure of the mentoring encountered in the Talking to Learn project at the centre of this paper. Timperley (2001, p113) identified a number of features underpinning the conduct of effective mentoring conversations; these included: 
- basing dialogue on observed data;

- $\quad$ sharing responsibility for identifying strengths and problems;

- discussing reasons for particular practices being strengths or problems;

- establishing the assumptions underlying the student teacher's practice;

- $\quad$ giving advice with reasons; and

- inquiring about the consequences of the advice.

These features are activities which create particular cultural-discursive (language) and social-political (relational) conditions and enable a shared reponsibility for practice development to emerge between the mentor and the PST. Along with the principles of dialogic pedagogies (outlined in the section below), these features were utilised in the development of the program of training and support for mentor teachers in the Talking to Learn project. As a development from the Timperley study, the Talking to Learn project required both the mentors and PSTs pairs as co-producers of the practice to: name the issues, initiate dialogue, share the responsibility for improvement, check that the agenda was shared, summarise observations and disclose their evaluations in connection to dialogic pedagogies, ask for reactions, explore differences and design ways to make adjustments for future practice.

In many studies, mentoring is reported to be conducted between a more experienced teacher and the novice in a one-to-one situation. It typically involves a mentoring dialogue which refers to 'the formal two-way conversation between a mentor teacher and a PST or beginning teacher' (Hennissen, et al., 2011, p 1050). Often these mentoring dialogues are conducted as a part of a formal assessable component of the PSTs practicum placement (Edwards-Groves \& Hoare, 2012; Tillem, et.al. 2011). There are three major points of difference between other mentoring studies and the mentoring reported in this paper. First, the mentoring conversations or dialogues took place between the experienced teacher and two PSTs who work together in a paired situation; this difference is one which is new in the descriptions of mentoring. Second, the mentoring practices reported in this paper are less formal in the sense that, although mentoring forms part of a bone fide classroom based project and teachers participated in some initial mentor training, mentoring is situated outside the confines of the formal practicum assessment regime (which was typical in this research site). It forms part both a complimentary and supplementary university-school initiative aiming to develop quality teaching practices. Third, the mentoring focus reported in this paper is mainly centred on the development of classroom interaction and dialogic pedagogies, a feature which is seldom reported on in the literature.

\subsection{Dialogic Pedagogies - a Focus for in Situ Mentoring Conversations}

In school education, the social-political relationship between child and adult, learner and teacher is always accomplished in language. Since the progressive impetus of educators such as John Dewey (1916), teachers and researchers around the world (Alexander, 2008; Bakhtin, 1981; Barnes, 1976; and Wells, 1981 for example) have challenged the notion that learning is a simple knowledge transfer from teacher to student. Their research has called for dialogic pedagogies as classroom interaction practices which aim to leverage student learning through particular talk moves that open up the communicative space of the classroom into a shared platform for deeper learning, meaning making, participation and engagement with the topic (Edwards-Groves, Anstey \& Bull, 2014).

Based on Alexander's work, informed by the thinking of Bakhtin (1981), this paper connects to the notion that dialogue allows participants to create new meanings and new understandings, rather than simply reproducing previously connected understandings. Dialogic pedagogies (Myhill, Jones \& Hopper, 2006) are practices which promote critical thinking and inquiry between teachers and students through genuine inquiry-based dialogues (Myhill, Jones \& Hopper, 2006, p. 25). Hence, the notion of dialogic pedagogies is a term which not only describes the interactions in classrooms, but importantly for this study, also refers the interactions experienced in mentoring conversations conducted between PSTs and their teacher mentors; forming what is described as a 'dialogic turn' in social and educational practice (Edwards-Groves, Anstey \& Bull, 2014).

\subsection{The 'Talking to Learn' Project}

The Talking to Learn project formed part of a two-year Faculty of Education study entitled "The Study of Teaching" conducted in a rural Australian university. The project was designed in response to an overarching call for teacher education to be structured around developing and understanding core practices (Grossman, Hammerness \& McDonald, 2009 and Reid, 2011). The Talking to Learn project was a specific Bachelor of Education degree initiative focused on developing dialogic pedagogies among PSTs as a core teaching practice (based on the work of Robin Alexander, 2008) from the beginning of their course. It was designed as a collaborative project between the university and a local school district office; and each iteration was conducted over the first semester of the four year Bachelor of Education course.

The project involved groups of 6-10 PSTs (arranged in pairs) entering classrooms for a weekly two hour period to 'practice interacting' with small groups of students. PSTs were organised to work in pairs as a strategic move to enable a mechanism of peer support when practicing with students and discussing practice development with mentors (acting as 
another 'set of eyes'). This shifted the power ratio to also enable PSTs to experience a sense of shared learning, shared accountability and collegiality with peers.

Mentoring conversations were conducted each week after the in-class practice sessions of teaching (nine in total). These mentoring conversations were anchored in actual practical experiences - as evidence or data - and involved substantive feedback through more critical conversations about the specific development observed and experienced. These experiences, or actions, formed the evidence (after Timperley, 2001) PSTs would draw on as they described, interpreted and re-interpreted their developing practices. Conversations focused specifically on developing the following dialogic pedagogies:

i. $\quad$ sustaining and extending responses

ii. demonstrating active listening through body language, further comment or reframing

iii. allowing appropriate wait time for thinking

iv. giving encouragement and specific feedback and responses that focused on building the dialogue

v. providing specific [and stage appropriate] curriculum information

vi. 'vacating the floor' so students had opportunities to direct talk

(Adapted from Churchill, 2011, p. 265)

PSTs and teacher mentors (released from their schools) attended additional workshops (four hours in total) that provided specific training about conducting mentoring conversations focused on developing dialogic pedagogies; these were facilitated by program designers (including the author). Based on the structure described by Timperley (2001), training involved providing a suggested structure: i) reviewing previous learning; ii) critiquing, responding to and guiding practice development; and iii) negotiating the future focus and collaborative goal setting. Additionally, teacher mentors met regularly (in three two-hour reflection and feedback meetings) throughout the semester to discuss their experiences and share professional readings.

\section{Method}

\subsection{The Broader Study}

The broader study, to which this paper relates, was a two-year qualitative project investigating the influence of the Talking to Learn intervention project (Edwards-Groves \& Hoare, 2012). This particular paper focuses on the following research questions;

i. What is the substantive nature of the dialogue between PSTs and their mentors as they engage in mentoring conversations after PSTs 'practise' teaching children in classrooms?

ii. How do mentoring conversations unfold in the moment-by-moment exchanges between PSTs and their classroom teacher mentors?

To address this question, the study drew on a model of Participatory Action Research (Carr \& Kemmis, 1986) where first year PSTs from a rural Australian university, were guided by teacher mentors (from six primary schools) and university academics to deliberately set about to understand and develop dialogic pedagogies. The Action Research methodology was selected as a model as it offered the researchers and the participants (teachers and PSTs) scope for shaping, reshaping and sharing learning across the semester of implementation and across the life of the project.

Ethics approval was sought and granted from the Charles Sturt University Human Ethics in Research Committee. Informed consent was obtained from the relevant teacher mentors and from PSTs who volunteered in the research component of the project; both groups of participants were free to withdraw at any stage.

\subsubsection{Participants}

In the broader study, 16 classroom teacher participants (over the two year period of the study) were nominated and recruited by the district school office to participate as classroom teacher mentors for PSTs in the Talking to Learn project. These teachers were selected by the education consultants from the district office according to years of experience and identified expertise in using more dialogic pedagogies. Upon the recommendations from the district office, researchers approached the particular classroom teachers, as a purposive selection method to participate in the research. Purposive selection enables the researcher to represent instances of participant cases which are both typical and/or desirable for the purposes of the study (e.g. in this case experienced classroom teachers who engage in more dialogic pedagogies) (Freebody, 2003, p. 78). As outlined in more detail below, teachers were provided with ongoing professional development by the researchers about conducting mentoring conversations and dialogic pedagogies. They were also provided with a certificate of participation in professional development (as required by the particular accrediting board in the state of New South Wales, Australia). 213 from 236 PSTs volunteered over the two years to 
participate in the practical in-school project; from this, 72 PSTs also agreed to participate in the research component. PSTs were given a certificate of participation which could form part of their developing portfolio. Note, in this research context there was approximately a ratio of 3:1 female to male (which mirrored the gender ratio for the general student intake of undergraduate primary education students).

This paper focuses on data collected from participants (two PSTs and a classroom teacher mentor) from one practical classroom situation. The focus on the classroom interactions was critical in examining the authentic nature of learning to teach within the 'realities' of the classroom context. Classroom teacher mentor, Amelia, was nominated by the district office as an 'experienced quality teacher'; she had been teaching for 26 years. Like other participating teachers, Amelia participated in an introductory session outlining the purposes of the Talking to Learn project and the research. She agreed to participate in the research which involved mentoring PSTs, audio-recording classroom lessons and mentoring sessions with PSTs and participate in follow-up focus group interviews. Note: all names are pseudonyms.

Two PSTs Toby (a male 21 years) and Mel (a female 19 years), who feature in the single case analysis below, were among 72 other first year PSTs who volunteered to participate in the research component of Talking to Learn project. Mel was a school leaver and had little experience with children except for babysitting cousins; Toby had left high school three years earlier, and since had worked in cafes and coached an under 12s football team in his local area. Mel and Toby were randomly paired, since many first year students did not know each other prior to university. They firstly participated in the weekly in-school practical component as a supplementary dimension to their compulsory course learning (conducted over nine weeks); and secondly, the research. The practical component involved PSTs going into classrooms in school settings to observe teaching-in-action, to 'practice interacting' with small groups of students and engage in follow-up mentoring conversations with experienced classroom teachers and their peer. The research component involved recording at least three small group interaction sessions with students from the classroom, the follow-up mentoring conversations with the classroom teacher mentor and a final focus group interview.

\subsubsection{Data collection and Analysis}

Data presented in this paper were gathered in one primary school using a range of qualitative methods over nine weeks including recorded classroom observations and mentoring conversations, semi-structured interviews and field notes (as per methods used for the broader study). In particular, the corpus of field data included video recordings and transcriptions of three 'practice teaching sessions' involving pairs of PSTs interacting with a small group of students. Each classroom teacher and pairs of volunteer PSTs were issued with a small audio recorder for the duration of the study to record their conversations and small-group interactions. Recorded mentoring conversations between PSTs and their mentor teacher were gathered each week after the PSTs practiced particular dialogic teaching strategies; and a post-project semi-structured focus group interview (Mertens, 1998) with PSTs and the mentor teacher. These interviews were conducted to build participant accounts and associated attributions of participant experiences and explanations of the conduct and practice of mentoring conversations (Freebody, 2007).

To study the nature of the dialogue between PSTs and teacher mentors in mentoring conversations and how they unfold in the moment-by-moment interactions, data from three audio-recorded mentoring conversations were transcribed as a record of the actual discursive production of the talk-in-interaction (Drew \& Heritage, 1992; Freebody \& Freiberg, 1995). Transcripts of recorded talk-in-interaction enable the close and continual examination of participants' practices; in turn, these afford the researcher the opportunity to elicit the intricacies of social actions (Freebody, 2007). Transcripts of mentoring conversations (as naturally occurring data) were closely examined to elicit themes about: i) the conduct of mentoring conversations (the structure and organisation), ii) how mentoring unfolded discursively as sequences of interaction in sequence (the orchestration) (Freiberg \& Freebody, 1995), and iii) how these produced displays of learning among PSTs (what was talked about). Analysing the transcripts of the mentoring conversations and follow-up interviews included a series of passes, or readings, of the talk-in-interaction (Freebody, 2003). It involved an initial close reading of the data to elicit commonly occurring broad themes which emerged across the corpus; this was followed up with subsequent readings to explore some of the visible features and particularities of the mentoring conversations and interviews. These multiple readings enabled the sets of analytical, topical and contextual relevances to emerge as findings and presented in the next section.

The purposeful selection of one case for this paper was a deliberate move to interpret the nature of the mentoring conversations which were being enacted in the Talking to Learn program. Analysing single cases of interaction as it happens in its context is valuable when the research goal is to study how dialogue is organised and the practices by which $t$ is produced (Schegloff, 1987), as it the case in this paper. Moreover, when concern rests with understanding, elucidating and describing social action as it is enacted in interaction, focusing on a single case as it is produced provides analytic machinery which deals with illuminating how episodes of talk are constituted 'in the real world' (Schegloff, 1987, p 102). 


\section{Results}

This section presents a detailed examination of one mentoring conversation selected from the larger corpus; the limitation of space prohibits a larger number of data to be presented. This is aimed to illustrate how mentoring conversations unfold interactively; that is, how the mentoring conversations were actually experienced by the participants in the moment-by-moment happeningness of the session. Presenting one example, rather than multiple segments from a larger number of data enables the reader to capture a more coherent and holistic essence of the flow and focus of a typical mentoring conversation. It also enables the reader to track the conversation through the particular sequences as they are experienced. Therefore, for the purposes of this article, a fine-grained case of one mentoring episode will be presented to provide an in-depth analysis of:

i. how teacher mentors conducted mentoring conversations - the nature of the questions, comments and feedback provided;

ii. the focus and interactive structure of the conversations-in-action as mentors and PSTs (based on the framework provided by Timperley, 2001):

a. reviewed previous learning;

b. critiqued, responded to and guided practice development; and

c. negotiated the focus and collaborative goal setting;

iii. how PSTs responded to and participated as co-producers of the conversations as they unfolded.

It is important to note that, as expected, variations in how these conversations unfolded were found between the different teacher mentors. The case presented was relatively typical in relation to form and function but was purposefully selected due to the high level of coherence and focus across the interaction sequences. Mentoring conversations in the Talking to Learn program, such as the one presented, generally lasted for approximately 15-20 minutes. The following mentoring conversation (drawn from the larger corpus) was facilitated by Amelia, classroom teacher mentor, with the two PSTs Toby and Mel.

\subsection{Learning Dialogic Pedagogies through Critical Mentoring Conversations}

In this transcript, Amelia facilitated the mentoring conversation with the two PSTs (Mel and Toby) after they had worked in pairs practicing interacting with a group of five Year 5 students ( 9 and 10 year olds in Australia). It is the third in-class practice teaching session from the sequence of nine that the PSTs participated for the Talking to Learn program. The nine teaching sessions were determined by the classroom teacher's existing teaching program. This particular session was conducted after Mel and Toby had been practicing teaching a small group of children about environmental sustainability issues in Antarctica.

\subsubsection{Reviewing and Reflecting on Experiences: Excerpt 1}

This excerpt is the beginning segment of the mentoring conversation (numbered in sequence). Here Amelia initiated the topic of the conversation around the 'practice focus' (what they were trying to improve) for each pre-service teacher which had been identified and negotiated after the previous weeks mentoring conversation.

1. Amelia (Classroom Teacher Mentor): Now see your focus was to practice 'wait time' and involvement. Toby, last week you asked yourself, do I balance my questions, and allow wait time and do I vacate the floor? And Mel you were looking at, do I keep the student's involved and focused. So were they involved and focused, Mel?

2. Mel (Pre-service Teacher): Most of the time, sometimes Leon got a bit distracted and you had to like say "Come on - what do you think?" So it was like you had to keep him focused.

3. Amelia: So why do you think that was? Why do you think he would get distracted?

4. Mel: I don't know, he was like excited and then he'd start talking about Antarctica, and then he started talking about animals, but they weren't related to Antarctica, and it was just hard to get him back on track.

5. Amelia: Is there a way that you think you could have gotten him focused?

6. Mel: He could of maybe had a turn at the computer or something, yeah, take more control of the researching instead of Nellie, Nellie likes to be on the computer all the time/

7. Toby (Pre-service Teacher): /Nellie's in charge. Yep, so maybe even we could have given them all some time - "Right okay Leon, now it's your turn". Let's get in there and actually shift the control, 
because yeah, he was one that I noticed, he'd kind of stands up the back looking around, he was quiet. Moni was often on task, but in a loud way.

8. Amelia: Yes, but you get used to noticing if the students are on task and what that actually means by what they are talking about.

9. Toby: Tell me about it - she just keeps talking, like "Mr Davis what do you think of this?"

10. Amelia:/Yeah, so see she is on task, involved, but she does it in a very loud over the top way/

11. Mel: /Yeah you can't shut them down like that because they're still on task/

12. Amelia: /No, whereas to get Leon back on track you could move towards the edge of the group and then he might be looking over there but you shift his eyes by where you are standing too. ....think about how maybe you are getting him in.

13. Mel: /Yeah she likes it, yeah.

14. Amelia: And that's not a problem, so maybe next week say "right Leon you can hop in now".

15. Mel: Swap, yep.

16. Toby: Say, "Your computer man, and then Gemma". She was quiet too but I tried to get her involved. Well see they could all be giving feedback to each other as well about what they are finding and searching for, not just standing there.

17. Amelia: Why would that help?

18. Toby: So that tells me they're all in there and involved, enjoying it, so it's just a matter of keeping them involved.

19. Mel: I just got her to write down the stuff too, involve her that way.

As the interaction unfolded (turns 1-19), Amelia established the episode as a democratic experience of co-learning (Darwin, 2000; Jaipal, 2009); PSTs had opportunities for initiating questions and comments. Amelia's questions directed the PSTs to focus their reflections on noticing particular 'interactional' aspects on the lesson they had experienced; this constituted the evidence for considering possible solutions and interactive alternatives. This practice acted not only as a form of awareness raising but drew attention to particular features of interaction in the teaching which may have been taken for granted had it not been highlighted by Amelia's talk.

In a democratic move, Amelia shifted the control of the problem identified by the PSTs back to them through questions such as "Were they involved and focused?"(turn 1), "Is there a way that you think you could have gotten him focused?" (turn 5). Amelia maneuvered the talk towards having Toby and Mel think critically, interpretively and consequentially about the interaction as a pedagogical approach which rationalised the activity (what students were doing), their responses (what students were saying) and the outcomes of the exchange (what resulted). She did this through questions such as, "So why do you think that was? Why do you think he would get distracted?" (turn 3).

Since the conversation was based on evidence - Mel and Toby's actual and recent experience interacting with students in small groups - the responses given were highly contextualised and based both on their developing knowledge of the dynamics of that group of students (in practice) and of dialogic pedagogies (in theory). Through evidentiary talk they showed they could think analytically through the interaction and the student's lack of focus on the task to make pedagogically valid responses or interpretations. For instance Mel's suggestion for Leon to "maybe have a turn at the computer, to take more control of the researching instead of Nellie" (turn 6), or Toby's comment, "Well see they could all be giving feedback to each other as well about what they are finding and searching for, not just standing there" (turn 16). These responses were critical in that they reflected their developing repertoire of 'teacherly' practices and theoretical understandings.

This segment illustrates that these PSTs after only six weeks into their course were beginning to orient to their teaching practices in relation to practice architectures; for example, the sayings (using the language 'shifting control', 'giving feedback'), doings (standing back, sharing time on the computer, where they should stand in the interaction) and relatings (student control of the computer, giving feedback to each other). In particular, Toby's comments to "actually shift the control" (turn 7) and "they're all involved, enjoying it" (turn 18) show two main points:

1. Toby was beginning to take up the sayings or cultural-discursive dimension of teaching (e.g. the language 'shifting control' has entered his linguistic practice) as he publically translated his experience into particular pedagogical frames (Edwards, 1995) as a demonstration he was not only entering the professional discourse but also the practice; and

2. By focusing on 'practicing and interacting', Toby was enabled to search for and articulate pedagogical 
rationales for practice as it happened.

The classroom experience provided the direct evidence from which the PSTs could draw on to discuss teaching practice in critical, evidentiary ways and the mentoring conversation itself provided the communicative space (the material-economic arrangements) for this to happen. In one way the mentoring episode experienced by Mel and Toby could be described as a focused and critical learning conversation.

\subsubsection{Critiquing, Responding to, and Guiding Practice Development: Excerpt 2}

As the exchanges continued (next in Excerpt 2), Amelia drew specific attention to the details of PSTs practicing questioning to meet the personal goals set by Toby.

20. Amelia: And see next week what we'll do is the same kind of thing so you can practise more of this... and actually having you generating questions before hand so you are prepared, that helps to ask a balance of questions, as you are thinking about Toby. So what kinds of questions could we ask to help us to research?

21. Toby: More than literal, the surface type questions.

22. Mel: Because yeah I found it hard to ask more critical questions because I don't really know much about Antarctica so I couldn't ask questions.

23. Toby: That's why I was doing it, yeah? But they were all the same types.

24. Mel: Yeah I didn't ask many questions.

25. Amelia: Yeah but there was a purpose in that too Mel, in that the kids actually had to do the work, think about what sort of information they needed.

26. Mel: Yeah that was like vacating the floor a bit, so/

27. Amelia: Yes, why? What does that connect up to?

28. Mel: Well, ah, giving them time to actually do the work and the thinking without you giving them the answers.

29. Amelia: So the next step will be... is actually lifting the level of what they get on paper and lifting the level of their talk, we can do that by our questioning/

30. Mel: /And even today when one of them said "there's penguins", that's all.../

31. Toby: /And all they said was "it's cold".

32. Amelia: Yeah, "there's penguins" and "it's cold" is a lower level response, so things like that next week I'd be going/

33. Toby: /It's actually minus 50 degrees and when it's winter time it's like minus 100

34. Amelia: ... normally I would say, "well what kind of word is "cold", and not let that go. So we're actually going to actually lift that level ... of what they're actually saying and writing. So if I got you all to go back and look at what have they actually written, what's the substance of it, what kind of vocab have they used, that's where we're kind of heading//

35. Toby: //It's more open, much more open, like they ask questions and we ask questions and encourage them to ask more questions, they learn from that. That's the type of teaching I want to do...

36. Mel: Yes I feel good because they ask interesting and challenging questions; they just kept asking questions to each other too.

37. Amelia: And even the questions that they ask is a result of the questions you have been asking, ... like they could articulate their answers quite well. That kind of learning is very helpful, them asking questions of each other. It is also a way to hand the control of the learning to them, for you to vacate the floor. It's a way to show what they know too. So next week we'll have a look at those and just see how they respond.

In this sequence (turns 20-37), the mentoring conversation was critical (analytical, interpretive and explanatory) and focused on learning at two levels:

i. first, the learning of the students in the class as the mentor and PSTs discussed how to raise the level of the vocabulary through questioning (e.g. turns 29-37); and

ii. second, the learning of the PSTs as they made explicit connections to levels of questioning and between students questioning each other as way of 'vacating the floor' (e.g. turn 12 above, turn 26). 
This interaction sequence unfolded instructively; that is as pedagogical practice (Edwards, 1995). The teacher mentor orchestrated the conversation as a form of critical pedagogy. Amelia gave explicit instruction and a high degree of specificity about the level of student's responses (turn 32), lifting the level of student responses (turn 34) and the substance of student responses (turn 37). Amelia, at this point, takes on a critical explanatory role as she guided the thinking of PSTs Toby and Mel so that they articulated more reasoned responses about the classroom interactions they were actually practicing. Here the nexus between the theory of dialogic pedagogies and practice formed a crucial dimension of learning teaching practices through the practice arrangements Amelia orchestrated through her mentoring.

Importantly, Amelia modeled 'dialogic pedagogies' (Alexander, 2008) in the orchestration of the mentoring conversation. As the episode unfolded, she provided opportunities for the PSTs to extend their responses (turns 25, 27, 29), build dialogue and critical thinking (turns 25,27 above, and 47 below), and provide specific [and stage appropriate] information (turns 29,32). These are key elements of enacting dialogic pedagogies. Additionally, her feedback directly responded to the comments and questions offered by the PSTs (see for example, turn 37) as demonstrations of enacting shared responsibility and co-learning. Crucially, feedback was provided at 'teachable moments' to feed forward to alternative and improved ways of interacting. The responsiveness of the feedback took the PSTs' focus directly to the details of the interactive patterns they were learning through practicing. Making these explicit from the outset oriented PSTs directly to the important features of dialogic pedagogies. It also demonstrated the critical dimension of the mentoring that the PSTs encountered as they were 'enabled' to explore through talk the quality of their own interactions through dialogic talk practices that were characterised by analytic, interpretive and explanatory conversations with their mentor. In this case, the mentoring practices provided the communicative space for the conversation between the teacher mentor and the PSTs to be interpretative. In the longer term, learning to interpret one's own practices from the beginning of their teaching degree is arguably a crucial dimension to learning to facilitate quality interactions between PSTs and children in classrooms. In the shorter term, this aspect of mentoring practice reflected the deeply critical nature of their talk, and further furnished the substance of conversation (the sayings) which consequently took place and shaped the negotiated focus for development.

\subsubsection{Negotiating the Focus and Collaborative Goal Setting: Excerpt 3}

This segment illustrates how goal setting was socially accomplished through the conversation as it unfolded as talk-in-interaction.

38. Amelia: Now, is there a new question that you would pose for yourself, something specific to think about working on for next time?

39. Toby: Do I balance my questions and wait time, do I do those? I am not sure. Did you tick that I did vacate the floor?

40. Mel: No, but you did sort of.

41. Toby: But I did?

42. Mel: Yeah you did vacate the floor more, but I think yours still is the questions, and the wait time.

43. Toby: Just keep my questions, then?

44. Mel: Yeah. You asked a lot of questions but they were the same, so yeah maybe work on that and just the wait time.

45. Toby: Balance my wait time with questions/

46. Amelia: /Yeah, still the balance between them is needed.

47. Toby: Yep. But then it goes quiet, and I don't like quiet.

48. Amelia: Think about that, what is the quiet doing, what does it mean for learning?

49. Toby: I suppose giving them time to think for themselves without being interrupted, or someone else just giving the answer so they don't have to think.

50. Mel: Yeah. And then they sort of talk between each other too, so.

51. Toby: Yeah which is good. What's another question, goal I could do?

52. Mel: I think, the same one.

53. Toby: ... so more getting used to the silence. But I actually need to do more in-depth questions? Because with the self-evaluation, ..., do I listen more to their answers? .. do I think and reflect on what they have said? I don't think I did much... I do remember the actual responses, but I didn't get them to extend them in any way, just move on. So that's a good one. 
54. Mel: Getting them to ask their own questions too, you know.

55. Amelia: So can you see how by actually getting them to pose questions and to think more carefully it will actually help with their ability to search and to look for information. ...So actually looking at pushing the level of response they're giving you, so if they say "It's really cold", a kindergarten child could tell you that Antarctica is "cold", we want more specific language appropriate for Year 5, so rather than "really cold", what could we say? And so on.

In this final segment (turns 38-55), the conversation shifted to focus on personal goal setting, based particularly on developing and refining dialogic pedagogies. For instance, Amelia guided Toby's thinking and decision making as he puzzled over his learning focus (see turns 38, 48, 55). With focused support from his peer and the mentor - acting as co-learners throughout the exchange - Toby identified (tentatively at first) questioning, wait time, vacating the floor, listening carefully to students responses to extend thinking and vocabulary. These features of enacting dialogic pedagogies - for example, vacating the floor so that students have more control over the talk in lessons - were not generally taken up as focus areas for development for these PSTs in their regular practicums in this research site. Significantly, it appeared that the mentoring with its focus on interaction and dialogue, elevated understandings of dialogic pedagogies to a higher level of prominence than otherwise would have been possible.

The excerpts from this particular mentoring conversation illustrated that each episode unfolded as 'collaborative analytic dialogues' (Edwards-Groves, 2003). These did not only include critical reflection and substantive dialogues between mentors (like Amelia) and PSTs (like Mel and Toby), but extended the repertoire of consciousness about the details of their practice development. This was enabled by the distinctiveness of the practice architectures of mentoring conversations in this case (and others like it). Specifically, it was the dedicated focus on the use and development of understandings of the role of dialogic pedagogies for learning as an effective classroom strategy (Alexander, 2008) which was a crucial dimension of the mentoring encounters. As highlighted by Hudson (2004) and Timperley (2001), it was the focused nature of conversations between the mentor and PSTs which proved to be pivotal for developing strong theory practice connections.

\subsection{Participant Perspectives on the Role and Influence of Mentoring}

Participating in mentoring conversations, like the episode above, aimed to provide opportunities for PSTs to reflect on and critique practice in order to interpret and explain experiences, and to build knowledge and a theoretical base around the classroom exchanges experienced and observed (Hudson, 2004; Timperley, 2001). As the above case illustrated, for PSTs like Mel and Toby, the high level of specificity in mentoring conversations on dialogue and timely feedback enabled them to recognise their own interactive practices and to explicitly connect these to the influential nature of talking for learning for students in classrooms. To exemplify, consider this interview response from Toby:

[Through the mentoring] I learnt that I need to ask more open questions allowing the students to take the floor and also to get them to talk amongst themselves. That way, they learn, and grow in knowledge of each other, as the student who understands can solidify their own knowledge and for the student who does not, they may learn from their friend or peer. Working with Amelia, it was like being in a team, with no judgment.

It was the participation in interactional sequences in the contextually authentic site of the classroom, as suggested by Edwards et al. (2004), that provided the authentic experience and evidence upon which to facilitate and participate in mentoring conversations. Toby's comment suggested PSTs were able to explicitly connect their learning about their practice with the learning of students in classrooms. Further, Toby recognised what he needed to practice and why. Significantly, from the beginning of their course, PSTs like Toby and Mel were guided to interpret not just their observations (as in Hennissen, et al., 2011) but connected their practical in-practice experiences - as evidence - to the theoretical frameworks for dialogic pedagogies. Mentoring conversations provided the communicative and collaborative space for this to happen. Reciprocally, it was also the mentoring conversations that enabled the 'practicing' to be refined and developed in connection to theory; it was an interdependent dimension of the mentoring. These experiences were connected ecologically; with each constituting and being constituted by the other. Importantly, PSTs recognised the democratic and collaborative nature of the practices they were participating in - "working in a team" as Toby suggested - as they were guided to interpret, critically reflect on and evaluate their practice development within an interdependent relationship (Darwin, 2000) and collaborative social-political arrangements. To "practice without judgment" was identified by Toby and other PSTs as an important feature of the process.

Feedback as an interactive feature was recognised by Mel as she evaluated the influence of mentoring conversations on her learning:

The whole feedback thing was I reckon the most important part of the project, it helped me to know where to improve... it was based on what I was doing... and we didn't have the pressure of being formally assessed. 
The mentoring helped encourage and support us in how they [mentors] observed us with the students and how we worked with them. It was excellent because I could really understand why thinking and talking about talk was so important for students learning.

Encouragement and support was recognised by Mel to be an important characteristic of the feedback provided by the mentor "which assisted them to really understand". Such interview responses illustrated that PSTs acknowledged that learning about teaching practice through the interactions experienced in mentoring conversations were not simply externally determined or constrained by assessment (Tillem, et al. 2011), but that they were participants in courses-of-action in classrooms with the capacity to shape and transform the classroom experience (Edwards-Groves \& Hoare, 2012). Through the mentoring process, it seemed PSTs developed deep understandings about their responsibilities for engaging in dialogic pedagogies as they acknowledged an "understanding as to why thinking and talking about talk was so important for students learning".

These accounts oriented to the pedagogical nature of mentoring conversations as PSTs described their learning. Further to this, they described the nature and influence of dialogic pedagogies, in particular the interactional influences and expectations that embody effective classroom practice. For instance Toby (above) was able to theorise how 'vacating the floor' enabled students to learn from each other. This demonstrated that the mentoring conversations in which he participated, enabled him to not only take on the professional discourse in more analytic ways, but be accountable for connecting it to the theories encountered at university. He was being 'enculturated' or being stirred in to the cultural-discursive dimensions of practice teaching practice (Edwards-Groves, 2003; Kemmis, et al., 2014).

Learning about teaching practice through practicing and critically reflecting on their experiences was a central outcome for the mentoring conversations; highlighted following by Amelia, classroom teacher mentor, in her interview:

With the PSTs this year, they didn't give the children the answers, their questioning had developed by the end of the eight weeks, ... they were able to draw the information out of the kids without telling them what to put on the page... At the start you could see them thinking about how they were going to say things, and so you could see that it was a process for them to let something come out, when they were questioning it was a lot of leading questions, they were giving the answers to the children, or letting the children know what they wanted them to say, and a lot of them picked up on that after the first session, like they were saying "oh my gosh I can't believe I even asked that question"... One thing about the process was that we had time, time to learn, time to practise, and time to adjust their practices. Time and regularity were really the keys, we really got to know and trust each other...

As suggested by Amelia, the time and regularity were influential in enabling the development of particular kinds of relatings or social-political arrangements. This led to a 'relational trust' between the mentor and PSTs and between the PSTs themselves which, in turn, created conditions which enabled collaborative and co-learning practices to emerge. In addition, PSTs needed time to translate their experiences into the professional discourse (Edwards, 1995) and so be 'stirred in to' or enter the 'sayings' of the profession. Amelia continues:

So that was really interesting watching their growth ... and the way that they were so open to any kind of feedback ... We didn't have anyone throwing their hands in the air saying it was too hard, or they didn't understand what was being asked of them or they weren't prepared to participate. They were just coming into it ready to learn... And that's just because, it has to be because they've had small group interactions... at the same time it was about them talking directly about what they experienced and trying to use professional ways to describe it... they've had support of a teacher through the mentoring conversations... the conversations were key, although it took a few weeks for those conversations to really become two-sided, like a lot of it [at the beginning] was me just talking to them or having to draw some responses out of people to begin with...

In this excerpt, Amelia orients to the reciprocity between her actions as a mentor and those of the PSTs, in her acknowledgement of both her support and their openness to learn and accept feedback. Her comments also point to both the pedagogical nature of the conversations and the complexity of learning teaching practice as she described the growth experienced by PSTs as they had to "learn to interact with children in classrooms" at the same time to "learn to participate in the conversations" whilst taking on the professional discourse to describe their experiences. It was evident that both Amelia, like other teacher mentors, began to view mentoring as an essential and valuable pedagogical arrangement which enabled the learning and development of teaching practice. Amelia goes further:

By the end of it that was becoming a lot more open, everyone was contributing and it was a real conversation... which after time ..they were able to take the theory and then try it out and put it into practice and apply it in the classroom and see how it went. I really enjoyed being able to guide them at such an early stage of their career. They could begin to understand what teaching is really about.

Woven through her comments Amelia recognised that participating in focused conversations assisted PSTs to develop, 
understand the nature of their development and ultimately, as a pedagogical practice, transform their teaching and understanding of it. Over time, the PSTs began to learn to participate in what Amelia described as "real conversations". These were both dialogic and analytic, grounded in the evidence of their experiences and focused on learning to teach as PSTs sought and accepted constructive feedback, set goals and worked on them and monitored their own development. According to Amelia, this did not happen automatically; PSTs needed time to learn to participate both in the classroom as a teacher and also time to learn to engage in focused and more analytic learning conversations. Amelia's comments also give rise to the evolving processes of democratic and collaborative participation (Darwin, 2000). These developed over time as critical learning conversations that provided opportunities for focused and critical dialogic reflection, which then enabled an increasingly reflexive relationship between learning teaching practice at university and within the practice context of classrooms.

The learning of practices occurs in specific sites (the classrooms in the schools and universities in which they are found). As acknowledged by Toby and Mel, the role of mentoring conversations in classrooms as a site for learning teaching practice is crucial; these emerged as the phenomenological reality where mentors and PSTs engaged in the everyday practice of teaching and learning. Importantly, for this paper, being able to interpret learning practices from the vantage of the site (or classroom) gives authenticity, character and distinctiveness to the mentoring practices studied and experienced. Examining one mentoring conversation enabled a close study of how the conversations unfold naturally as sequences of interaction; such a focus does however limit the scope for interpreting the influence of mentoring conversations on actual teaching practices and narrows the scope for understanding what this looks like in various contexts. Although the participants do orient to their own change in interview data, their accounts alone do not allow a demonstration of the change over time.

\section{Discussion}

In this final section, the key features which emerged from the analysis of interview data and segments from a selected mentoring conversation will be summarised. It was found that learning to teach and learning about teaching was strengthened under particular conditions or practice architectures; in particular, when mentoring conversations demonstrated practice architectures that were pedagogical, collaborative, analytic and dialogic. This involved mentors facilitating conversations that were:

i. critical - PSTs challenged to be analytic, to justify or interpret, extend and critique their own and others' actions and responses;

ii. focused on learning - PSTs lead beyond arbitrary descriptions of practice to examine their actions and interactions about:

a. the learning of students in classrooms, and

b. their learning as novice teachers.

Attention to these levels to be sustained throughout the conversation.

iii. based on evidence - substantive dialogues utilising evidentiary talk (connected to authentic actions and interactions as experiences) to exemplify learning and extrapolate meanings;

iv. connected to theory - conversations framed as being accountable to the professional discourse enables PSTs to become insiders to the profession as they translate practices into language, activities and concepts informed by theory;

v. responsive - timely feedback is provided; communicative spaces created for collaborative goal setting.

It was found the mentoring conversations, as they were experienced by participants in this study, enables a re-definition of mentoring in teacher education:

Mentoring is a dialogic pedagogical practice. It is a communicative and transformative practice whereby two or more people engage in learning conversations facilitated by an experienced other. These conversations are focused on learning, critical in nature, based on evidence from experiences and actions, accountable for making connections between theory and practice and involve timely responsive feedback and collaborative goal setting. The intersubjective dimensions of mentoring practice - their sayings, doings and relatings - are coherent and comprehensible to each interactive participant.

This definition captures the nature of the mentoring through the conversations encountered by PSTs involved in the Talking to Learn project. It suggests that effective mentoring conversations are pedagogical, collaborative, analytic and dialogic, and opens up the question of what 'learning teaching practices' actually looks like in the moment by moment unfolding of a practice. Hudson (2004) suggests this type of 'specific mentoring' is significant for guiding the development of teaching practice among PSTs. As such, mentoring conversations need to accompany the learning 
encountered in teacher education courses in the university setting, they are pivotal in leading PSTs (through collaboration, support and guidance) towards the development of knowledge and skills in interpreting, critiquing and adapting interactive practices for themselves (Edwards-Groves \& Hoare, 2012).

\section{Conclusion}

This paper examined the overlapping nature of 'dialogue for learning' on two levels: first, the role of dialogue in mentoring conversations among PSTs and teacher mentors; and second how, through these conversations, PSTs develop understandings about 'dialogic pedagogies' when it is the explicit object of learning. Examining transcripts of mentoring conversations and follow-up interviews with PSTs and teacher mentors revealed the social intricacies and substantive nature of the dialogues encountered in their mentoring conversations. Results provide a dynamic description of the particular conditions and practice arrangements that stimulate and support the practice development of PSTs as they learn teaching practice. Importantly, this paper informs the field how this transpires in the moment-by-moment interactions encountered in mentoring conversations. These were learning conversations which were found to be pedagogical and explanatory, collaborative, analytic and interpretative, dialogic and evidence-based. Further, it was found that framing conversations around dialogic practices and situating these in the genuine space of the classroom as a site for learning teaching practice made the focus authentic and timely for first year PSTs.

Specifically, the study reported in this paper offers a re-definition of mentoring in and for teacher education. It describes the particularities of mentoring as conversations-in-action and shows how these are critical in that they are characterised by focused interactions which are pedagogical, collaborative, analytic and dialogical. Empirically the data showed how mentoring conversations are critical when they are analytical, interpretive and explanatory. It illustrates the in-practice realities of how mentoring unfolds intersubjectively, collaboratively and discursively as sequences of interaction and how these interactions produce displays of learning among PSTs. Furthermore, in this study, the use of dialogic pedagogies to conduct mentoring conversations also emerged as a productive pedagogical strategy for PSTs learning to teach. This finding points directly to the need for teacher educators, and classroom teacher mentors who support the learning of PSTs in authentic classroom situations, to take up more dialogic practices in their own interactions with PSTs. It is recommended that to enter the teaching profession as critical inquirers and knowledgeable practitioners such practices will enable the communicative spaces for PSTs, as learners of the teaching profession, to become analytical, interpretive and critical in and of the profession they are seeking to participate in.

Finally, understanding the nature of classroom learning as interactive dialogic spaces and the critical influence of mentoring conversations as a core dimension of teaching and developing dialogic practices among PSTs requires a focal position in teacher education globally. Further, the paper illustrates the importance of connecting theoretical propositions made within teacher education programs with critical mentoring conversations between PSTs and teacher mentors as a medium to form a significant nexus between theory and practice; one which aligns learning to teach within the particular projects, circumstances and sites in which teaching is understood and enacted.

\section{Acknowledgements}

I wish to acknowledge Rhonda Hoare for the significant contribution of the development of the Talking to Learn Program, in particular her role in designing the support for classroom teachers who conduct mentoring conversations with PSTs.

\section{References}

Alexander, R. (2008). Towards dialogic teaching: Rethinking classroom talk. Cambridge: Dialogos.

Allen, T. D. (2003). Mentoring others: A dispositional and motivational approach. Journal of Vocational Behavior, 62, 134-154.

Ambrosetti, A. \& Dekkers, J. (2010). The Interconnectedness of the Roles of Mentors and Mentees in Pre-service Teacher Education Mentoring Relationships, Australian Journal of Teacher Education; 35(6), http://ro.ecu.edu.au/ajte/vol35/iss6/3

Bakhtin, M. (1981). The Dialogic Imagination: Four Essays. Edited M. Holquist and trans. C, Emerson and M. Holquist. Austin, TX: University of Texas Press.

Barnes, D. (1976). From Communication to Curriculum. Harmondsworth: Penguin.

Bransford, J., Brown, A., \& Cocking, R. (1999). How people learn: Brain, mind, experience, and school. Washington, DC: National Academy Press.

Carr, W., \& Kemmis, S. (1986). Becoming Critical: Education knowledge and action research. London: Falmer Press. Churchill, R. (2011). Teaching: making a difference. Qld, Australia: John Wiley \& Sons. 
Clutterbuck, D., \& Ragins, B. (2002). Mentoring and diversity. Oxford: Heinemann.

Collins, C. (2004). Envisaging a new education studies major: what are the core educational knowledges to be addressed in pre-service teacher education? Asia-Pacific Journal of Teacher Education, 32(3), 227-240.

Darwin, A. (2000). Critical reflections of mentoring in work settings. Adult Education Quarterly, 50, 197-211.

Day, C. (1999). Professional development of teachers. Buckingham: Open University Press.

Dewey, J. (1916,). Democracy and Education. Digitalised in 2009 by Watchmaker Publishing, US: Merchant Books.

Drew, P. \& Heritage, J. (eds) (1992). Talk at work: Interaction in institutional settings. Cambridge: Cambridge University Press.

Eby, L. T., McManus, S. E., Simon, S. A. \& Russell, J. E. A. (2000). The protégés perspective regarding negative mentoring experiences: The development of a taxonomy. Journal of Vocational Behavior, 57, 1-21.

Edwards, A., Gilroy, P. \& Hartley. D. (2004). Rethinking teacher education: Collaborative responses to uncertainty. London: Routledge.

Edwards, A. (1995). Teacher education: partnerships in pedagogy? Teaching and Teacher Education, 11(6), 595-610.

Edwards-Groves, C. (2003). On task: Focused literacy learning. Newtown, Sydney: Primary English Teaching Association.

Edwards-Groves, C., Anstey, M., \& Bull, G. (2014). Classroom Talk: Understanding dialogue, pedagogy and practice. Newtown, Sydney: Primary English Teaching Association Australia.

Edwards-Groves, C., \& Hoare, R. (2012). "Talking to Learn”: Focusing teacher education on dialogue as a core practice for teaching and learning. Australian Journal of Teacher Education, 37(8), Aug, 82-100

Egan, B. A. (2009). Learning conversations and listening pedagogy: the relationship in student teachers, and developing professional identities. European Early Childhood Education Research Journal, 17(1), 43-56

Fenimore-Smith, J. K. (2004). Democratic Practices and Dialogic Frameworks. Journal of Teacher Education, 55(3), 227.

Freebody, P. (2003). Qualitative Research in Education: Interaction and Practice. London: SAGE Publications Ltd.

Freebody, P., \& Freiberg, J. (1995). Analysing literacy events in classrooms and homes: Conversation-analytic approaches. In P. Freebody, C. Ludwig \& S. Gunn. Everyday literacy practices in and out of schools in low socio-economic urban communities. Report to the Commonwealth Department of Employment, Education and Training, Curriculum Corporation, 1, 185-372.

Graham, S., \& Thornley, C. (2000). Connecting Classrooms in Pre-service Education: conversations for learning. Asia-Pacific Journal of Teacher Education, 28(3), 235-245.

Green, B. (ed.) (2009). Understanding and Researching Professional Practice. Rotterdam, The Netherlands: Sense Publishers.

Grove, K., Strudler, N., \& Odell, S. (2004). Mentoring toward technology use: Cooperating teacher practice in supporting student teachers. Journal of Research on Technology in Education, 37(1), 85-109.

Grossman, P., Hammerness, K., \& McDonald, M. (2009). Redefining teaching, re-imagining teacher education, Teachers and Teaching, 15(2), 273-289

Haggarty, L. (1995). The Use of Content Analysis to Explore Conversations between School Teacher Mentors and Student Teachers. British Educational Research Journal, 21(2), 183-197.

Heikkinen, H. L. T., Jokinen, H., \& Tynjälä, P. (2008). Reconceptualising mentoring as a dialogue. In G. Fransson \& C. Gustavsson (Eds.), Newly qualified teachers in Northern Europe: Comparative perspectives on promoting professional development, (pp. 107-124). Gävle: University of Gävle.

Hennissen, P., Crasborn, F., Brouwer, N., Korthagen, F., \& Bergen, T. (2011). Clarifying Pre-Service Teacher Perceptions of Mentor Teachers' Developing Use of Mentoring Skills. Teaching and Teacher Education: An International Journal of Research and Studies, 27(6), 1049-1058.

Hudson, P. (2004). Specific mentoring: a theory and model for developing primary science teaching practices. European Journal of Teacher Education, 27(2), 139-146.

Jacobi, M. (1991). Mentoring and Undergarduate Academic Success: A Literature Review. Review of Educational Research, 61(4), 505-532.

Jaipal, K. (2009). Re-envisioning mentorship: PSTs and associtate teachers as co-learners. Teaching Education, 20(3), 
257-276.

Kemmis, S. (2012). Action Research and Practice Theory. Unpublished manuscript. School of Education, Charles Sturt University: Australia.

Kemmis, S., \& Grootenboer, P. (2008). Situating praxis in practice: Practice architectures and the cultural, social and material conditions for practice. In S. Kemmis, and T.J. Smith (Eds.), Enabling praxis: Challenges for Education, 37-64. Rotterdam: Sense.

Kemmis, S., Wilkinson, J., Edwards-Groves, C., Hardy, I., Grootenboer, P., \& Bristol, L. (2014). Changing Practices, Changing Education. Singapore: Springer.

Kwan, T., \& Lopez-Real, F. (2005). Mentors' perceptions of their roles in mentoring student teachers. Asia-Pacific Journal of Teacher Education, 33(3), 275-287.

Lai, E. (2005). Mentoring for in-service teachers in a distance teacher education programme: views of mentors, mentees and university teachers. Paper presented at the Australian Association for Research in Education International Education Research Conference, Parramatta.

Lave, J., \& Wenger, E. (1991). Situated Learning: Legitimate Peripheral Participation. Cambridge: Cambridge University Press.

Le Cornu, R. (2010). Changing roles, relationships and responsibilities in changing times. Asia-Pacific Journal of Teacher Education, 38(3), 195-206.

Love, K. (2009). Literacy pedagogical content knowledge in secondary teacher education: Reflecting on oral language and learning across the disciplines. Language and Education, 23(6), 41-60.

Martinez, K. (1998). Supervision in preservice teacher education: speaking the unspoken. International Journal of Leadership in Education, 1(3), 279-296.

Merriam, S. (1983). Mentors and Protégés: A critical review of the literature. Adult Education Quarterly, 33, 161-173.

Mertens, D. (1998). Research methods in education and psychology: Integrating diversity with quantitative and qualitative approaches. Thousand Oaks, C.A: Sage.

Racionero, S., \& Poldras, M. (2010). The Dialogic Turn in Educational Psychology. Journal of Psychodidactics, 15(2), 143-162.

Reid, J. (2011). A practice turn for teacher education? Asia-Pacific Journal of Teacher Education, 39(40), 293-310.

Roche, G. R. (1979). Much ado about mentors. Harvard Business Review, 57, 14-28.

Sacks, H. (1974). On the analysability of stories by children. In R. Turner (Ed.), Ethnomethodology, (pp. 216-232). Harmondsworth: Penguin Books Ltd.

Schatzki, T. (2002). The site of the social: A philosophical account of the constitution of social life and change. University Park, TX: University of Pennsylvania Press.

Schegloff, E. (1987). Analysing Single Episodes of Interaction: An Exercise in Conversation Analysis. Social Psychology Quarterly, 50(2), 101-114

Strong, M., \& Baron, W. (2004). An analysis of mentoring conversations with beginning teachers: suggestions and responses. Teaching and Teacher Education, 20(1), 47-57.

Tillem, H. H., Smith, K., \& Leshem, S. (2011). Dual roles - conflicting purposes: a comparative study on perceptions on assessment in mentoring relations during practicum. European Journal of Teacher Education, 34(2), 139-159.

Timperley, H. (2001). Mentoring Conversations Designed to Promote Student Teacher Learning. Asia-Pacific Journal of Teacher Education, 29(2), 111-123.

Weaver, C. (2009). Reading Process, 3rd Ed. Portsmouth: Heinemann

Wells, G. (1981). Learning through interaction: The study of language development. London: Cambridge University Press.

Woodruff, E., \& Brett, C. (1999). Collaborative Knowledge Building: Preservice Teachers and Elementary Students Talking to Learn. Language and Education, 13(4), 280-302.

\section{(c)) EY}

This work is licensed under a Creative Commons Attribution 3.0 License. 